\title{
Biochemical Effects of Vitamin A on Bladder Cancer
}

ISSN: 2640-9208

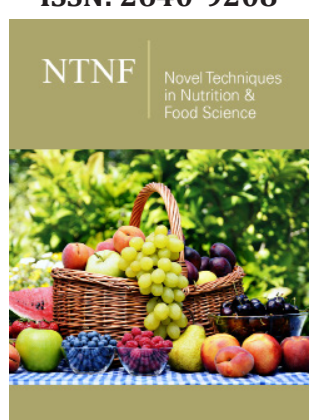

*Corresponding author: Ster Irmak Sav, Faculty of Health Sciences, Department of Nutrition and Dietetics, Istanbul Bilgi University, Turkey

Submission: 想February 12, 2021

Published: 留 April 07, 2021

Volume 5 - Issue 5

How to cite this article: Tunay Dogan, Ster Irmak Sav. Biochemical Effects of Vitamin A on Bladder Cancer. Nov Tech Nutri Food Sci. 5(5). NTNF. 000623. 2021. DOI: 10.31031/NTNF.2021.05.000623

Copyright@ Ster Irmak Sav. This article is distributed under the terms of the Creative Commons Attribution 4.0 International License, which permits unrestricted use and redistribution provided that the original author and source are credited.

\author{
Tunay Dogan ${ }^{1}$ and Ster Irmak Sav ${ }^{2 *}$ \\ ${ }^{1}$ Department of Basic Oncology, Division of Cancer Genetics, Istanbul University, Oncology \\ Institute, Turkey \\ ${ }^{2}$ Faculty of Health Sciences, Department of Nutrition and Dietetics, Istanbul Bilgi University, \\ Turkey
}

\section{Introduction}

Among all urological cancers, Bladder Cancer (BC) is the tenth most common type of cancer worldwide, with approximately 549,000 new cases per year and 200,000 mortality. It is four times more common in males than females and is frequently seen in the sixth and seventh decades [1]. In addition to its negative effects on public health, BC is one of the cancer types with the highest cost of treatment due to its frequent recurrence [2]. For these reasons, the role of dietary factors, especially vitamins, in preventing BC has been studied frequently. In this mini review, we aimed to summarize that experimental and epidemiological studies investigating the relationship between vitamin A and BC.

Vitamin A is a fat-soluble micronutrient and must be taken with dietary or supplementary since it cannot be produced in the human body. When taken in excess, it can be stored in the liver and adipose tissue. The vitamin A family exists in two forms: preformed vitamin A (retinaldehyde, retinol, and retinoic acid) and provitamin A carotenoids ( $\alpha$-carotene, $\beta$-cryptoxanthin, and $\beta$-carotene). Provitamin $A$ is the precursor of retinol, the most active metabolite. Retinol is found in high amounts in eggs, dairy products, and fish oils. Carotenoids are found in high amounts in orange and yellow fruits and dark green leafy vegetables. Although lycopene, lutein, and zeaxanthin are carotenoids, they do not have vitamin A activity biologically. In contrast, synthetic retinoid compounds have vitamin A activity [3].

Many studies have used human tumor xenografts in nude mice or human cancer cell lines to investigate the effects of vitamin A metabolites and synthetic retinoids on BC and other types of cancer [4]. The results report that these compounds have chemo preventive, therapeutic, or anticancer effects through cell differentiation, regulation of apoptosis, or cell growth arrest [5,6]. Because of their antioxidant activity, carotenoids have prompted researchers to investigate their modulatory effects on carcinogen metabolism [7], and the potential benefits of carotenoids in heavy smokers BC patients are often debated.

One of the oldest studies examining the relationship between $\mathrm{BC}$ and vitamin A was conducted by Toyoshima et al. [8]. The researchers, in their studies using the NBT-II rat urinary bladder cell line, showed that adding $1 \mathrm{UI} / \mathrm{mL}$ of vitamin $\mathrm{A}$ to the medium did not alter cell proliferation and aggregation, but inhibited keratinization reversibly [8]. A later study by Tchao et al. [9] was shown that vitamin A prevents keratinization in NBT-II cell aggregates but does not have an inhibitory effect on aggregate formation [9]. Cohen et al. investigated the effects of vitamin A level on N-[4-(5-Nitro-2-furyl)-2-thiazolyl] formamide-induced BC in rats and they reported that vitamin A deficient rats seemed to speed up the carcinogenic process, with Urinary Bladder Tumor (UBT) emerging earlier. In contrast, in hypervitaminosis A-rats, UBT development occurred more slowly, and squamous metaplasia and squamous cell neoplasia did not occur [10]. In the study conducted by Squire et al. [11], they reported that 13-cis-retinoic acid is protective on the development of N-methyl-N-nitrosourea-induced BC in rats and inhibits the development of preneoplastic or neoplastic lesions in the bladder epithelium [11]. The study by Grubbs et al. [12] reported that 13-cis-retinoic acid inhibits the N-butyl-N-(4-hydroxybutyl)-nitrosamine-induced BC in rats [12]. Similarly, Sporn et al. [13] 
was reported that 13-cis-retinoic acid inhibited the development of N-methyl-N-nitrosourea-induced BC in rats [13]. In the study by Becci et al. [14] was reported that 13-cis-retinoic acid inhibited N-butyl-N-(4-hydroxybutyl)-nitrosamine-induced BC in C57BL/6 mice [14]. In the study of Miyata, et al. was stated that rats with hypervitaminosis A have increased resistance to N-butyl-N-(4hydroxybutyl)-nitrosamine-induced BC [15]. In a study conducted by Becci et al. [14] with a different approach, BC was formed with N-butyl-N-(4-hydroxybutyl)-nitrosamine in 344 rats, and the effect of delay in the administration of 13-cis-retinoic acid on BC inhibition was investigated. The results showed that the ability of 13-cis-retinoic acid to prevent bladder carcinogenesis was not weakened even by a nine-week delay in initiating retinoid feeding [16].

Mathews-Roth et al. [17] investigated the effect of supplementary $\beta$-carotene on $\mathrm{N}$-butyl-N-(4-hydroxybutyl)nitrosamine-induced BC in male B6D2Fi mice. Researchers reported that mice taking supplementary $\beta$-carotene developed significantly fewer tumors than untreated mice [17]. After experimental studies have shown its protective effects on $\mathrm{BC}$, there has been an increase in epidemiological studies examining the relationship between vitamin A and BC. In the study conducted by Risch et al. [18] on 826 BC patients and 792 healthy control groups, it was reported that dietary $\beta$-carotene or retinol had no protective effect on bladder cancer [18]. In the study conducted by Steineck et al. [19] on 418 BC patients and 511 healthy control groups, no relationship was found between BC and dietary vitamin levels, but it was reported that intake of vitamin A supplements may reduce the risk of BC [19]. In the study conducted by Nomura et al. [20] on 261 BC patients and 522 healthy control groups, it was reported that dietary and supplementary (total) carotenoids, retinol, and vitamin A were not associated with BC risk [20]. In the study conducted by Bruemmer et al. [21] on $262 \mathrm{BC}$ patients and 405 healthy control groups, it was shown that total vitamin A and retinol may have a protective effect on BC, unlike dietary $\beta$-carotene [21]. In the study of Michaud et al. on $320 \mathrm{BC}$ patients, no significant relationship was found between vitamin $\mathrm{A}$ and $\mathrm{BC}$ risk [22]. In the study conducted by Wakai et al. [23] on 297 BC patients' retinol and vitamin A can be protective on BC. Besides, dietary carotene has been reported to have a protective and 295 healthy control groups, it was shown that dietary effect only in BC patients who are heavy smokers [23]. In the study conducted by Zeegers et al. [24] on 569 BC patients and 3123 healthy control group, the relationship between retinol, $\alpha$-carotene, $\beta$-carotene, and $\beta$-cryptoxanthin intake and $\mathrm{BC}$ was evaluated and it was stated that only $\beta$-cryptoxanthin intake could have a protective effect on BC [24]. In a study conducted by Michaud et al. on 344 BC patients, the relationship between dietary vitamin $A, \alpha$-carotene, $\beta$-carotene and $\beta$-cryptoxanthin intake and $\mathrm{BC}$ was investigated, and none of them were reported to show a statistically significant level of protection. However, the researchers stated that their findings could not be generalized to non-smokers [25]. Nomura et al. [20] investigated the levels of retinol, $\alpha$-carotene, $\beta$-carotene, and $\beta$-cryptoxanthin from serum samples of $111 \mathrm{BC}$ patients and 111 healthy control groups using HPLC. The researchers saw that $\alpha$-carotene, $\beta$-carotene, and $\beta$-cryptoxanthin were statistically significant inverse correlated with $\mathrm{BC}$, but they reported the following the adjustment for the smoking pack-year, none of the reverse patterns remained significant [26].

In the study conducted by Castelao et al. [27] on 1592 BC patients and 1592 healthy control group, a statistically significant inverse relationship was found between dietary total carotenoid intake and BC [27]. Schabath et al. [28] investigated dietary total carotenoid intake in $423 \mathrm{BC}$ patients and 467 healthy controls and found that there was a statistically significant lower carotenoid intake in BC patients. Then, they investigated DNA damage from peripheral blood lymphocytes of $\mathrm{BC}$ patients and healthy controls by comet analysis. As a result of the study, the researchers reported that there is a statistically significant inverse relationship between carotenoid intake and DNA damage and that carotenoid intake may have a protective effect against DNA damage [28]. Holick et al. [29] in their study including 237 women with BC, investigated the relationship between $\mathrm{BC}$ intake with total vitamin $\mathrm{A}$, dietary $\alpha$-carotene, $\beta$-carotene, and $\beta$-cryptoxanthin, and it was reported that there was no statistically significant relationship [29]. Hung et al. [30] analyzed the plasma retinol, $\alpha$-carotene, $\beta$-carotene, and $\beta$-cryptoxanthin levels by HPLC in their study on $242 \mathrm{BC}$ patients and 204 healthy control groups. The researchers stated that $\alpha$-carotene and $\beta$-cryptoxanthin could have a statistically significant protective effect on $\mathrm{BC}$, and pointed out that BC could be prevented, especially in smokers, through diet [30].

Ozasa et al. [31] as a result of HPLC analysis of serum samples of 42 BC patients and 124 healthy control groups, reported that total carotenoids, especially $\beta$-carotene, were statistically significantly associated with a reduced risk of $\mathrm{BC}$, in contrast to serum retinol levels [31]. In the study of Garcia-Closas et al. [32] on 912 BC patients and 873 healthy control groups, it was reported that there was no statistically significant relationship between dietary retinol intake and BC [32]. Similarly, the study Kellen et al. [33] on $178 \mathrm{BC}$ patients and 362 healthy control groups stated that there was no statistically significant relationship between dietary retinol intake and BC [33]. In contrast to these two studies, Liang et al. [34] investigated retinol levels by HPLC from the plasma of 386 BC patients and 389 healthy controls and reported that the plasma retinol level was statistically significant protective for BC [34]. In the study conducted by Roswall et al. [35] on 322 BC patients, it was stated that unlike supplementary $\beta$-carotene, dietary $\beta$-carotene could be statistically significant protective for $\mathrm{BC}$ [35]. In the study conducted by Brinkman et al. [36] on 322 BC patients and 239 healthy controls, a statistically significant inverse relationship was found between total carotenoids intake and BC among elderly individuals [36]. In the study conducted by Hotaling et al. [37] on 330 BC patients, it was reported that taking supplementary $\beta$-carotene and retinol does not reduce the risk of $\mathrm{BC}$ [37]. In the study conducted by Ros et al. [38] on 856 BC patients, plasma carotenoid levels were analyzed by HPLC and it was reported that high plasma carotenoid levels could reduce the risk of BC. The researchers also stated that $\beta$-carotene level and Urothelial 
Cell Carcinoma (UCC) were statistically significant inverse related [38]. In the study conducted by Wu et al. [39] on 1117 BC patients and 1418 healthy controls, no statistically significant relationship was found between dietary vitamin A, $\alpha$-carotene and $\beta$-carotene intake and BC [39]. In a multiethnic study by Park et al. [40] on $581 \mathrm{BC}$ patients (152 women and $429 \mathrm{men}$ ), it was stated that high dietary vitamin $\mathrm{A}, \alpha$-carotene, $\beta$-carotene, and $\beta$-cryptoxanthin intake reduced the risk of $\mathrm{BC}$ among women, but the same results were not seen in male BC patients [40]. On the other hand, in the Alpha-Tocopherol, Beta-Carotene Cancer Prevention (ATBC) study conducted by Virtamo et al. [41] in Finland, it was reported that long-term supplementary $\beta$-carotene intake had no protective effect on urinary tract cancers in middle-aged male smokers [41].

Epidemiological studies indicate that vitamin A may have preventive effects on BC development, but the findings are inconsistent. For this reason, it will be more informative to examine meta-analysis. In the meta-analysis conducted by Tang et al. [42] in 2014, it was found that total vitamin A intake (OR: 0.82; $95 \%$ CI: $0.65,0.95$ ), total retinol intake (OR: 0.88 ; 95\% CI: 0.73, 1.02), and high blood retinol levels (OR: 0.64; 95\% CI: 0.38, 0.90) have been reported to have a protective effect on BC. Researchers also stated that there is an inverse relationship between carotenoids and $\mathrm{BC}$ risk [42]. In the meta-analysis conducted by Wu et al. [43] in 2019 , dietary $\beta$-cryptoxanthin intake (OR: 0.58; 95\% CI: 0.36 , 0.94), high blood $\alpha$-carotene (OR: $0.24 ; 95 \% \mathrm{CI}: 0.08,0.67$ ) and $\beta$-carotene levels (OR: 0.73; 95\% CI: 0.57, 0.94) has been reported to be inversely related to $\mathrm{BC}$ risk [43].

\section{Conclusion}

Although studies conducted in animal experimentation clearly show the inhibitory effect of vitamin A on bladder carcinogenesis, epidemiological studies are inconsistent. As a result, it seems that most of the studies state that vitamin A intake is associated with a reduced risk of $\mathrm{BC}$ in humans. The findings of studies dealing with the relationship between retinol and $\mathrm{BC}$ are variable. When the relationship between $\mathrm{BC}$ and $\alpha$-carotene, $\beta$-cryptoxanthin, and $\beta$-carotene are considered one by one, the results are inconsistent. However, there may be an inverse relationship between total carotenoid intake or serum carotenoid levels and BC risk. Using vitamin, A and other dietary factors might have effects on reducing $\mathrm{BC}$ risk, however, the number of studies that have investigated circulating concentration of micronutrients and other food components are limited. Therefore, further studies are needed with a larger sample.

\section{Competing Interests}

The authors declared they have no competing interests.

\section{References}

1. Bray F, Ferlay J, Soerjomataram I, Siegel RL, Torre LA, et al. (2018) Global cancer statistics 2018: GLOBOCAN estimates of incidence and mortality worldwide for 36 cancers in 185 countries. CA cancer journal for clinicians 68(6): 394-424.

2. Sloan FA, Yashkin AP, Akushevich I, Inman BA (2020) The cost to Medicare for bladder cancer care. European urology oncology, 3(4): 515-522.
3. Zinder R, Cooley R, Vlad LG, Molnar JA (2019) Vitamin A and wound healing. Nutrition in Clinical Practice 34(6): 839-849.

4. Niles RM (2004) Signaling pathways in retinoid chemoprevention and treatment of cancer. Mutation Research 555(1-2): 81-96.

5. Sporn MB, Roberts AB (1984) Role of retinoids in differentiation and carcinogenesis. J Natl Cancer Inst 73(6): 1381-1387.

6. Doldo E, Costanza G, Agostinelli S, Tarquini C, Ferlosio A, et al. (2015) Vitamin A, cancer treatment and prevention: the new role of cellular retinol-binding proteins. BioMed research international 2015: 624627.

7. Nishino H (1998) Cancer prevention by carotenoids. Mutation Research/ Fundamental and Molecular Mechanisms of Mutagenesis 402(1-2): 159163.

8. Toyoshima K, Leighton J (1975) Vitamin A inhibition of keratinization in rat urinary bladder cancer cell line Nara Bladder Tumor No. 2 in meniscus gradient culture. Cancer Research 35(7): 1873-1879.

9. Tchao R (1980) Keratinization and the effect of vitamin A in aggregates of a squamous carcinoma cell line NBT II. In vitro 16(5): 407-414.

10. Cohen SM, Wittenberg JF, Bryan GT (1976) Effect of avitaminosis A and hypervitaminosis A on urinary bladder carcinogenicity of N-[4-(5-nitro2-furyl)-2-thiazolyl] formamide. Cancer Research 36(7 Part 1): 23342339.

11. Squire RA, Sporn MB, Brown CC, Smith JM, Wenk ML, et al. (1977) Histopathological evaluation of the inhibition of rat bladder carcinogenesis by 13-cis-retinoic acid. Cancer Research 37(8 Part 2): 2930-2936.

12. Grubbs CJ, Moon RC, Squire RA, Farrow GM, Stinson SF, et al. (1977) 13-cis-Retinoic acid: inhibition of bladder carcinogenesis induced in rats by N-butyl-N-(4-hydroxybutyl) nitrosamine. Science 198(4318): 743-744.

13. Sporn MB, Squire RA, Brown CC, Smith JM, Wenk ML, et al. (1977) 13-cisretinoic acid: inhibition of bladder carcinogenesis in the rat. Science 195(4277): 487-489.

14. Becci PJ, Thompson HJ, Grubbs CJ, Squire RA, Brown CC, et al. (1978) Inhibitory effect of 13 -cis-retinoic acid on urinary bladder carcinogenesis induced in C57BL/6 mice by N-butyl-N-(4-hydroxybutyl) nitrosamine. Cancer Research 38(12): 4463-4466.

15. Miyata Y, Tsuda H, Miyasato K, Fukushima S, Murasaki GI, et al. (1978) Effect of vitamin A acetate on urinary bladder carcinogenesis induced by $\mathrm{N}$-butyl-N-(4-hydroxybutyl) nitrosamine in rats. GANN Japanese Journal of Cancer Research 69(6): 845-848.

16. Becci PJ, Thompson HJ, Grubbs CJ, Brown CC, Moon RC (1979) Effect of delay in the administration of 13-cis-retinoic acid on the inhibition of urinary bladder carcinogenesis in the rat. Cancer Research 39(8): 31413144.

17. Roth MM, Lausen N, Drouin G, Richter A, Krinsky NI (1991) Effects of carotenoid administration on bladder cancer prevention. Oncology 48(3): 177-179.

18. Risch HA, Burch JD, Miller AB, Hill GB, Steele R, et al. (1988) Dietary factors and the incidence of cancer of the urinary bladder. American Journal of Epidemiology 127(6): 1179-1191.

19. Steineck G, Hagman U, Gerhardsson M, Norell SE (1990) Vitamin A supplements, fried foods, fast and urothelial cancer. A case-referent study in Stockholm in 1985-87. International Journal of Cancer 45(6): 1006-1011.

20. Nomura AM, Kolonel LN, Hankin JH, Yoshizawa CN (1991) Dietary factors in cancer of the lower urinary tract. International Journal of Cancer 48(2): 199-205.

21. Bruemmer B, White E, Vaughan TL, Cheney CL (1996) Nutrient intake in relation to bladder cancer among middle-aged men and women. American journal of epidemiology 144(5): 485-495. 
22. Michaud DS, Spiegelman D, Clinton SK, Rimm EB, Willett WC, et al. (2000) Prospective study of dietary supplements, macronutrients, micronutrients, and risk of bladder cancer in US men. American Journal of Epidemiology 152(12): 1145-1153.

23. Wakai K, Takashi M, Okamura K, Yuba H, Suzuki KI, et al. (2000) Foods and nutrients to bladder cancer risk: a case-control study in Aichi Prefecture, Central Japan. Nutrition and cancer 38(1): 13-22.

24. Zeegers MPA, Goldbohm RA, Brandt PA (2001) Are retinol, vitamin C, vitamin $\mathrm{E}$, folate, and carotenoids intake associated with bladder cancer risk? Results from the Netherlands Cohort Study. British Journal of Cancer 85(7): 977-983.

25. Michaud DS, Pietinen P, Taylor PR, Virtanen M, Virtamo J, et al. (2002) Intakes of fruits and vegetables, carotenoids, and vitamins $\mathrm{A}, \mathrm{E}, \mathrm{C}$ in relation to the risk of bladder cancer in the ATBC cohort study. British journal of cancer 87(9): 960-965.

26. Nomura AM, Lee J, Stemmermann GN, Franke AA (2003) Serum vitamins and the subsequent risk of bladder cancer. The Journal of Urology $170(4$ Part 1): 1146-1150.

27. Castelao JE, Yuan JM, Dominguez MG, Skipper PL, Tannenbaum SR, et al. (2004) Carotenoids/vitamin C and smoking-related bladder cancer. International Journal of Cancer 110(3): 417-423.

28. Schabath MB, Grossman HB, Delclos GL, Hernandez LM, Day RS, et al. (2004) Dietary carotenoids and genetic instability modify bladder cancer risk. The Journal of Nutrition 134(12): 3362-3369.

29. Holick CN, Vivo I, Feskanich D, Giovannucci E, Stampfer M, et al. (2005) Intake of fruits and vegetables, carotenoids, folate, and vitamins A, C, E and risk of bladder cancer among women (United States). Cancer Causes \& Control 16(10): 1135-1145.

30. Hung RJ, Zhang ZF, Rao JY, Pantuck A, Reuter VE, et al. (2006) Protective effects of plasma carotenoids on the risk of bladder cancer. The Journal of Urology 176(3): 1192-1197.

31. Ozasa K, Ito Y, Suzuki K, Watanabe Y, Hayashi K, et al. (2005) Serum carotenoids and other antioxidative substances associated with urothelial cancer risk in a nested case-control study in Japanese men. The Journal of Urology 173(5): 1502-1506.

32. Closas RG, Closas GM, Kogevinas M, Malats N, Silverman D, et al. (2007) Food, nutrient and heterocyclic amine intake and the risk of bladder cancer. European Journal of Cancer 43(11): 1731-1740.
33. Kellen E, Zeegers M, Buntinx F (2006) Selenium is inversely associated with bladder cancer risk: a report from the Belgian case-control study on bladder cancer. International journal of urology 13(9): 1180-1184.

34. Liang D, Lin J, Grossman HB, Ma J, Wei B, et al. (2008) Plasma vitamins E and $\mathrm{A}$ and risk of bladder cancer: a case-control analysis. Cancer Causes \& Control 19(9): 981-992.

35. Roswall N, Olsen A, Christensen J, Dragsted LO, Overvad K, et al. (2009) Micronutrient intake and risk of urothelial carcinoma in a prospective Danish cohort. European Urology 56(5): 764-770.

36. Brinkman MT, Karagas MR, Zens MS, Schned A, Reulen RC, et al. (2010) Minerals and vitamins and the risk of bladder cancer: results from the New Hampshire Study. Cancer Causes \& Control 21(4): 609-619.

37. Hotaling JM, Wright JL, Pocobelli G, Bhatti P, Porter MP, et al. (2011) Long-term use of supplemental vitamins and minerals does not reduce the risk of urothelial cell carcinoma of the bladder in the Vitamins and Lifestyle study. The Journal of Urology 185(4): 1210-1215.

38. Ros MM, Mesquita HB, Kampman E, Aben KK, Büchner FL, et al. (2012) Plasma carotenoids and vitamin $\mathrm{C}$ concentrations and risk of urothelial cell carcinoma in the European prospective investigation into cancer and nutrition. The American Journal of Clinical Nutrition 96(4): 902-910.

39. Wu JW, Cross AJ, Baris D, Ward MH, Karagas MR, et al. (2012) Dietary intake of meat, fruits, vegetables, and selective micronutrients and risk of bladder cancer in the New England region of the United States. British Journal of Cancer 106(11): 1891-1898.

40. Park SY, Ollberding NJ, Woolcott CG, Wilkens LR, Henderson BE, et al. (2013) Fruit and vegetable intakes are associated with a lower risk of bladder cancer among women in the Multiethnic Cohort Study. The Journal of Nutrition 143(8): 1283-1292.

41. Virtamo J, Edwards BK, Virtanen M, Taylor PR, Malila N, et al. (2000) Effects of supplemental alpha-tocopherol and beta-carotene on urinary tract cancer: incidence and mortality in a controlled trial (Finland). Cancer Causes \& Control 11(10): 933-939.

42. Tang JE, Wang RJ, Zhong H, Yu B, Chen Y (2014) Vitamin A and risk of bladder cancer: a meta-analysis of epidemiological studies. World Journal of Surgical Oncology 12(1): 1-9.

43. Wu S, Liu Y, Michalek JE, Mesa RA, Parma DL, et al. (2020) Carotenoid intake and circulating carotenoids are inversely associated with the risk of bladder cancer: a dose-response meta-analysis. Advances in Nutrition 11(3): 630-643.

For possible submissions Click below:

Submit Article 